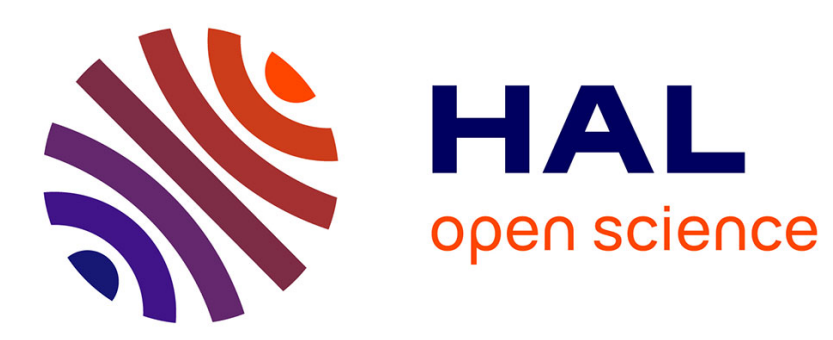

\title{
Influence of cold rolling and fatigue on the residual stress state of a metal matrix composite
}

E. Hanus, T. Ericsson, J. Lu, F. Decomps

\section{To cite this version:}

E. Hanus, T. Ericsson, J. Lu, F. Decomps. Influence of cold rolling and fatigue on the residual stress state of a metal matrix composite. Journal de Physique IV Proceedings, 1993, 03 (C7), pp.C7-1817C7-1820. 10.1051/jp4:19937288 . jpa-00251930

\section{HAL Id: jpa-00251930 https://hal.science/jpa-00251930}

Submitted on 1 Jan 1993

HAL is a multi-disciplinary open access archive for the deposit and dissemination of scientific research documents, whether they are published or not. The documents may come from teaching and research institutions in France or abroad, or from public or private research centers.
L'archive ouverte pluridisciplinaire HAL, est destinée au dépôt et à la diffusion de documents scientifiques de niveau recherche, publiés ou non, émanant des établissements d'enseignement et de recherche français ou étrangers, des laboratoires publics ou privés. 


\title{
Influence of cold rolling and fatigue on the residual stress state of a metal matrix composite
}

\author{
E. HANUS, T. ERICSSON, J. LU* and F. DECOMPS ${ }^{* *}$
}

\author{
Division of Engineering Materials, Department of Mechanical Engineering, Linköping University, \\ 58183 Linköping, Sweden \\ * Département Matériaux, Centre Technique des Industries Mécaniques, 52 av. Félix Louat, BP. 27, \\ 60304 Senlis cedex, France \\ ${ }_{* *}^{*}$ Régie Nationale des Usines Renault, Direction de la Recherche, 8-10 av. Emile Zola, 92109 Boulogne \\ Billancourt cedex, France
}

\begin{abstract}
The large difference in the coefficient of thermal expansion between the matrix alloy and the particle in a metal matrix composite gives rise to residual stresses in the material. In the present work the effect of cold rolling and four-point bending fatigue on the residual stress state of a silicon carbide particle reinforced aluminium alloy (AA 2014) has been investigated. The three dimensional stress state measured in both phases: matrix and reinforcement, has been determined by using an X-ray diffraction technique. It was found that cold rolling induces surface compressive macrostresses of about $-250 \mathrm{MPa}$, with a penetration depth around $2 \mathrm{~mm}$. The absolute values of the pseudomacrostresses in both phases are significantly reduced due to the single track rolling. Stress relaxation occurs during four-point bending fatigue.
\end{abstract}

\section{INTRODUCTION}

Aluminium alloys reinforced by ceramic particles offer higher stiffness and superior strength relatively to those of unreinforced alloys. They can furthermore be produced using standard metallurgical processes. However the large difference in coefficient of thermal expansion between matrix and reinforcement gives rise to residual stresses during manufacturing and subsequent heat treatment. Since these stresses are tensile in the matrix, they may be detrimental for the fatigue.

It is therefore of interest to apply a mechanical surface treatment in order to enhance the fatigue life of components by generating a compressive stress field at the surface of the material. This study presents the possibility of inducing compressive surface stresses by cold rolling and examines their stability during four point bending fatigue.

\section{THEORY}

Residual stresses in a metal matrix composite can be classified into two groups [1]. Macrostresses, which are homogeneous on a macroscopic scale, i.e. in a volume containing a large numbers of grains, are the same in both phases of the composite, and may occur due to cold rolling. Microstresses, which are homogeneous in small domains like a grain, may arise in the inhomogeneous distribution of plastic deformation on a microscale. They are different from one phase to another. The total stress at any point in the material is then the sum of these two components: macro- and microstress.

The experimental determination of microstresses would require the analysis of a single grain, which is not feasable. Diffraction however is an useful tool to study the stresses in individual phases of materials, it yields information about the average microstresses in the diffracting volume. In a two phase material, these pseudomacrostresses obey the following equilibrium [1]: 


$$
(1-f)<\mu_{\sigma_{i j}}>m+f<\mu_{\sigma_{i j}}>p=0
$$

where $f$ is the volume fraction of the particles, $\left\langle\mu \sigma_{i j}\right\rangle_{m} / p$ the pseudomacrostress tensor in the matrix / particles respectively.

Models based on the Eshelby's equivalent inclusion approach [2] have been applied to predict the elastic, thermoelastic and plastic behaviour of particulate reinforced metal matrix composites [3-4]. It is possible to calculate the stress state after a temperature drop (the particles and the matrix have different coefficient of thermal expansion) or after plastic straining (the two phases have different elastoplastic behaviour).

\section{EXPERIMENTAL DETAILS}

The metal matrix composite investigated here is a 2014 aluminium alloy reinforced by 15.5 volume percent of silicon carbide particles. The material was delivered by Cospray as extruded bars. The nominal size of the particulate reinforcement was determined by photosedimentation method: a median value of $9 \pm 1 \mu \mathrm{m}$ was obtained. A morphological study, performed on secondary electron images showed that the particles are rather aligned in the extrusion direction with an effective aspect ratio of $1.9 \pm 0.8$.

Two specimen geometries were used to study the influence of cold rolling (fig. 1). In a) a single track rolling was conducted on cylinders machined from an extruded bar. In b) the four point bending fatigue samples were heat treated to T6 prior to rolling under $9200 \mathrm{~N}$.

a)

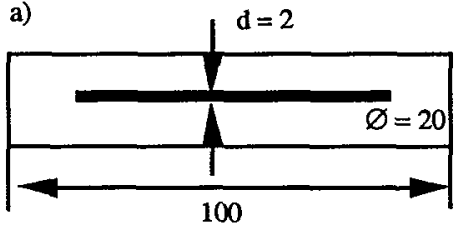

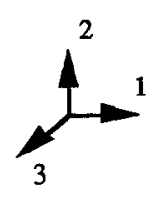

b)

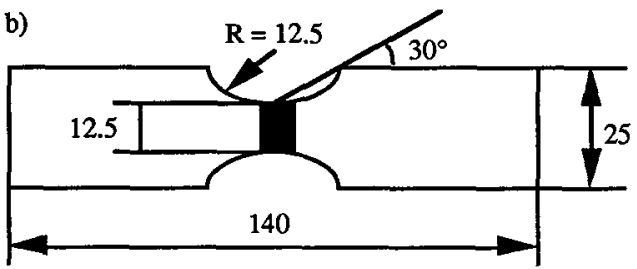

Figure 1. a) Single track and b) four point bending fatigue specimens (the rolling track is in black).

$\mathrm{X}$-ray stress measurements were performed using a Seifert diffractometer in psi mode. The radiation used was $\mathrm{Cu} \mathrm{K} \alpha$ from a fine focus X-ray tube run at $30 \mathrm{~mA}$ and $40 \mathrm{kV}$. The penetration depth, at $90 \%$, varies with the $\psi$-angle between $56 \mu \mathrm{m}$ for $\psi= \pm 45^{\circ}$ and $79 \mu \mathrm{m}$ for $\psi=0^{\circ}$. Since the grain size is about $3 \mu \mathrm{m}$, the diffracting volume contains a large number of grains. Seven $\psi$-angles coupled with three $\varphi$-angles were used in order to make a three dimensional stress analysis possible. The diffraction peaks were recorded with a position sensitive detector and fitted by a pseudo-Voigt function [4]. The diffracting planes and the associated X-ray elastic constants are shown in the following table.

\begin{tabular}{|l|c|c|c|}
\hline Phase & Plane $(\mathrm{h}, \mathrm{k}, \mathrm{l})$ & $1 / 2 \mathrm{~S}_{2}{ }^{*}\left(10^{-6} \mathrm{MPa}\right)$ & $\mathrm{S}_{1}{ }^{*}\left(10^{-6} \mathrm{MPa}\right)$ \\
\hline Al [Kröner model] & $(4,2,2)$ & 18.0024 & -4.4477 \\
\hline $\mathrm{SiC}[5]$ & $(3,0,6)$ & 2.7746 & -0.3765 \\
\hline
\end{tabular}

\section{RESULTS AND DISCUSSION}

To study the ability of cold rolling in inducing compressive macrostresses in the composite, four different conditions of the material have been investigated. (HT): heat treated for three hours at $500^{\circ} \mathrm{C}$ followed by a slow cooling in the chamber furnace down to room temperature. (AR): as received in a perpendicular section of an extruded bar, and (CR40/CR65): cold rolled along a single track under 800 and $1300 \mathrm{~N}$. The stress results are shown in fig. 2.

A three dimensionnal stress state is measured in the heat treated condition. Negligible macrostresses are observed, which is coherent with the fact that a slow cooling does not generate significant temperature gradients between the surface and the core of the sample. The measured stresses are also pure pseudomacrostresses which obey the equilibrium equation (1). 

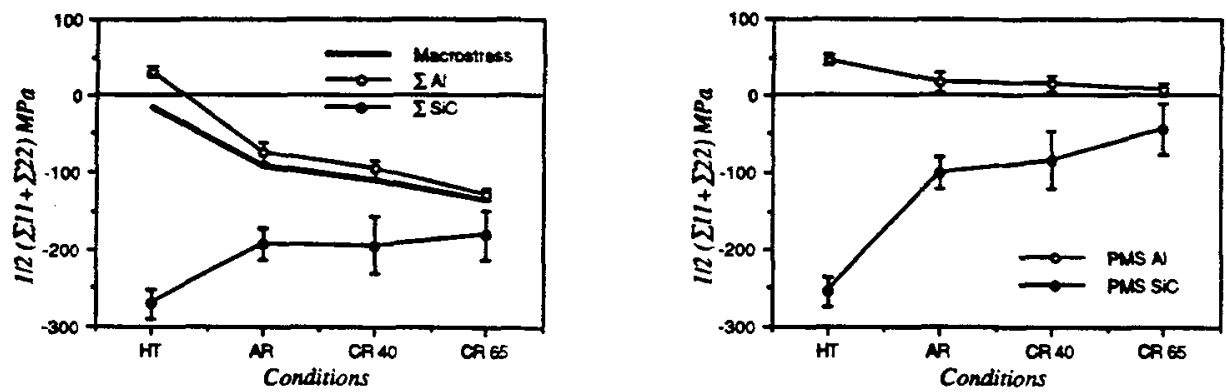

Figure 2. Total-, macro, and pseudomacrostresses (PMS) in the $\mathrm{Al}$ and $\mathrm{SiC}$ phases for the heat treated (HT), as received (AR) and cold rolled (CR40 and CR65) $2014+$ SiC.

By applying the Eshelby theory one can model the cooling fom $500^{\circ} \mathrm{C}$ down to room temperature in two steps: from $500^{\circ} \mathrm{C}$ down to $185^{\circ} \mathrm{C}$, where the relaxation mechanisms are assumed to be instantaneous, and from $185^{\circ} \mathrm{C}$ down to room temperature, where the composite behaves thermoelastically. The particles are assumed to be aligned, and their geometry is modelled by small ellipsoids with a circular cross section. With an aspect ratio of 1.45 , which fits in the experimental aspect ratio range, a very good agreement is found, as shown in table 2.

Table 2. Comparison between the Eshelby stress predictions and the experiments. Values in MPa.

\begin{tabular}{|l|c|c|c|c|}
\hline & \multicolumn{2}{|c|}{ Aluminium } & \multicolumn{2}{c|}{ Silicon carbide } \\
\hline & Experiment & Eshelby & Experiment & Eshelby \\
\hline Long axis 1 & $57 \pm 3$ & 57 & $-312 \pm 5$ & -311 \\
\hline Short axis 2 & $40 \pm 6$ & 41 & $-218 \pm 20$ & -222 \\
\hline Short axis 3 & $43 \pm 6$ & 41 & $-234 \pm 20$ & -222 \\
\hline
\end{tabular}

During the cold rolling the material is compressed perpendicularly to its surface, so that plastic flow occurs in the surface plane, while the inner part behaves elastically. The interaction between these two zones generates, as observed, compressive macrostresses in the surface layer. This effect is more pronounced in the direction perpendicular to the rolling direction, i.e directions 2 and 1 for geometries a) and b) respectively.

Of interest is the evolution of the pseudomacrostresses. They are the largest in the heat treated condition and decrease significantly due to the cold rolling. This trend can be qualitatively explained by the Eshelby theory. Withers et al. [3] derived the stress response to an applied load of a particulate reinforced metal matrix composite. By assuming no stress in both phases of the composite prior to loading, they found tensile stresses in the SiC phase and corresponding compressive stresses in the Al phase. In the realistic case where thermal residual stresses are present in the composite, one finds by superposition that a reduction in the magnitude of the microstresses is expected.

To study the penetration depth achieved by cold rolling, incremental electropolishing was carried out on a specimen of geometry b). The stress results without any correction for layer removal are shown in fig. 3.
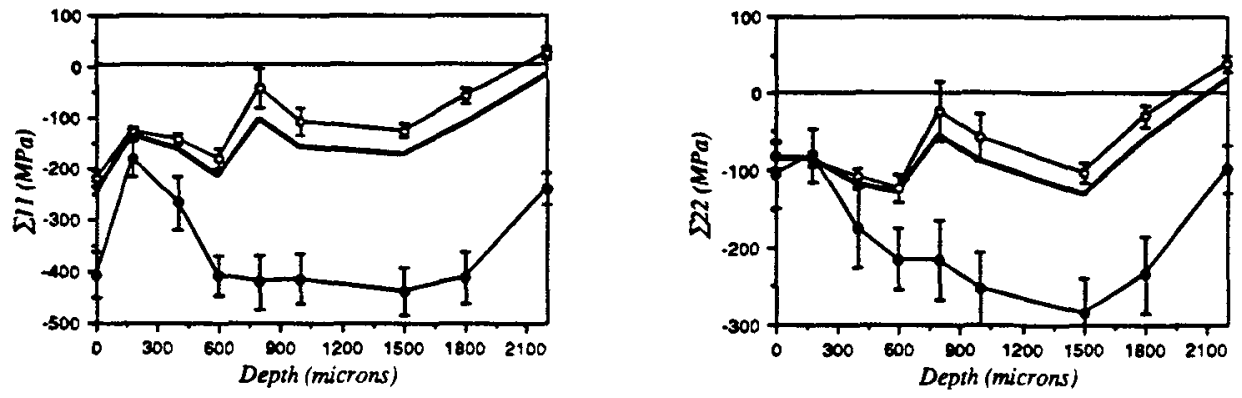
Figure 3. Depth stress profile in a T6 $-9200 \mathrm{~N}$ cold rolled $2014+\mathrm{SiC}$. The $\mathrm{Al}$ and SiC phases are represented by open and solid symbols respectively, the macrostress is depicted by a single line.

Several comments can be made on this stress profile. First of all a penetration depth of $2.1 \mathrm{~mm}$ is measured. This depth has been correlated to the diffraction peak width: the full width at half maximum decrease with depth from 1.2 downto $0.7^{\circ}$ at $2 \mathrm{~mm}$. Secondly a minimum in pseudomacrostresses is observed around $175 \mu \mathrm{m}$. This minimum shows that the maximum deformation occurs in the subsurface. A microhardness profile was conducted on another sample pointing out a maximum of work hardening in this region. Finally some additionnal experiments confirm that the pseudomacrostress state at depths around 2 $\mathrm{mm}$ is the one induced by the T6 treatment.

To study the stability of the stress state during fatigue, four point bending was used. The upper side is loaded in compression while the lower side is cycled in tension. Fig. 4 shows the surface stress evolution of a $9200 \mathrm{~N}$ cold rolled specimen cycled at $300 \mathrm{MPa}$ with a load ratio of 0 . The fatigue life is in that case about ten million cycles.
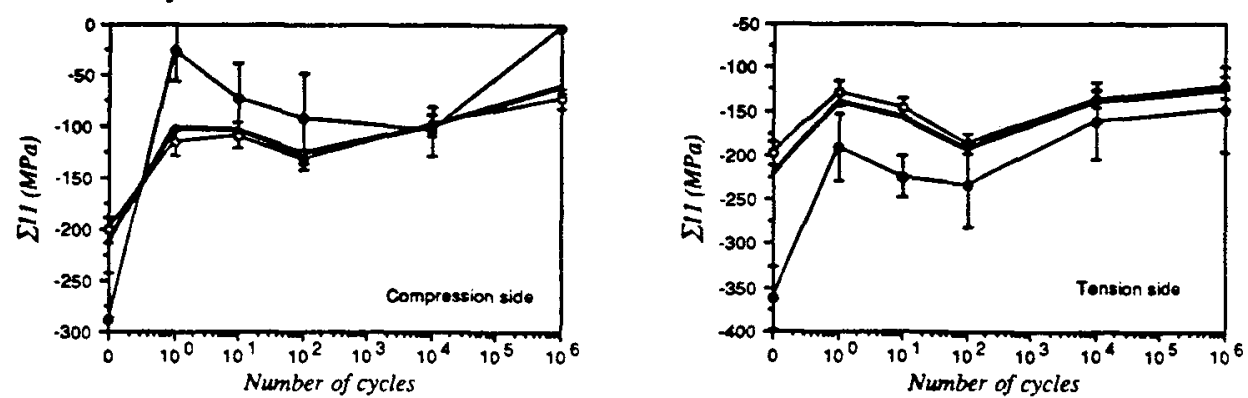

Figure 4. $\sigma_{11}$ evolution on the compression and tension loaded sides during four point bending fatigue under $300 \mathrm{MPa}$ of a $9200 \mathrm{~N}$ cold rolled $2014+\mathrm{SiC}$. The $\mathrm{Al}$ and $\mathrm{SiC}$ phases are represented by open and solid symbols respectively, the macrostress is depicted by a single line.

It can be seen that relaxation occurs predominantly in compression rather than in tension, the role of the first cycle being significant. A $71 \%$ reduction in macrostress is observed in compression while only a 43 $\%$ decrease is found in tension. This confirms that deformation takes preferentially place in compression [4].

\section{CONCLUSIONS}

Large compressive macrostresses can be induced by cold rolling, with a penetration depth of $2 \mathrm{~mm}$. A reduction in pseudomacrostresses with increasing plastic deformation was observed. The Eshelby model has been successfully applied to predict the residual stresses after a slow cooling from the solution temperature. Four point bending fatigue relaxes the surface residual stresses more on the compression loaded side than on the tension cycled one. The yielding due to the first cycle accounts for more than $75 \%$ of the total relaxation.

\section{REFERENCES}

[1] I. C. Noyan and J. B. Cohen in "Residual Stress: Measurement by Diffraction and Interpretation", Springer-Verlag (1987).

[2] J. D. Eshelby, Prog. Solid Mech., 2, 89 (1961).

[3] P. J. Withers, W. M. Stobbs and, O. B. Pedersen, Acta Metall., 37, 3061 (1989).

[4] C. Persson in "Residual Stress in Metal Matrix Composites after Plastic Straining and Thermal Cycling", Linköping Studies in Science and Technology, Licenciate Thesis n³32 (1992).

[5] M. Kurita, N. Ono, I. Ihara, and T. Yada, J. Soc. Mat. Sci., B7, 100 (1988). 